\title{
Biosynthesis of Peptidoglycan in Wall plus Membrane Preparations from Micrococcus luteus: Direction of Chain Extension, Length of Chains and Effect of Penicillin on Cross-linking
}

\author{
By A. WESTON,* J. B. WARD† AND H. R. PERKINS* \\ * Department of Microbiology, University of Liverpool, Liverpool L69 $3 B X$ \\ $\dagger$ National Institute for Medical Research, Mill Hill, London $\mathrm{NW}_{7}$ I $A A$
}

(Received 7 September 1976)

\begin{abstract}
SUMMARY
A wall + membrane preparation from Micrococcus luteus was used to synthesize radioactively labelled peptidoglycan. The newly synthesized peptidoglycan either was cross-linked by transpeptidation to existing wall or remained associated with the membrane fraction but was not cross-linked. The average biosynthetic chain lengths, calculated from the ratio of free reducing groups of muramic acid to total muramic acid, were 66 disaccharide units for cross-linked and 26 disaccharide units for the uncross-linked material. The latter value was confirmed by the release of lactyl peptide side chains by $\beta$-elimination. Benzylpenicillin $\left(\mathrm{I} \mu \mathrm{g} \mathrm{ml}^{-1}\right)$ inhibited cross-linking but not overall synthesis of glycan whereas at concentrations above Io $\mu \mathrm{g} \mathrm{ml}^{-1}$ overall glycan synthesis was slightly inhibited. In the presence of $100 \mu \mathrm{g}$ benzylpenicillin $\mathrm{ml}^{-1}$ the incorporation of disaccharide units to existing walls decreased to $25 \%$ of the control. This residual incorporation represented extension by transglycosylation of peptidoglycan already cross-linked to existing walls. Chains with an average length of between 30 and 45 disaccharide units were added during a $30 \mathrm{~min}$ incubation period. However, if incubation was continued for up to I $20 \mathrm{~min}$ (in the presence of $100 \mu \mathrm{g}$ benzylpenicillin $\mathrm{ml}^{-1}$ ) a considerable amount of the newly synthesized peptidoglycan was lost from the purified wall because autolytic enzymes were expressed in the wall + membrane preparation after the action of the antibiotic.
\end{abstract}

\section{INTRODUCTION}

Recently a novel system for the study of peptidoglycan biosynthesis was described (Mirelman, Bracha \& Sharon, 1972; Mirelman \& Sharon, 1972) in which crude wall and membrane preparations were used as the enzyme sources. The crude wall preparation incorporated radioactivity from the nucleotides UDP- $N$-acetylmuramyl-L-alanyl-Disoglutamyl-L-lysyl-D-alanyl-D-alanine, UDP- $N$-acetylglucosamine and the amino acid glycine into newly synthesized peptidoglycan. The advantage of this system over the membrane and particulate enzyme preparations used earlier (Anderson et al., 1965, I966) was that it not only catalysed the polymerization reactions but also attached the newly synthesized peptidoglycan to existing wall.

Low concentrations of penicillin inhibited not only the transpeptidation reactions but also the covalent binding of newly synthesized peptidoglycan to the existing wall (Mirelman, Bracha \& Sharon, 1974a). However, complete inhibition of incorporation from nucleotides into existing wall could not be achieved. Transglycosylation reactions, which were responsible for elongation of existing glycan chains, were insensitive to penicillin and thus a con- 
siderable number of disaccharide units were still linked to existing wall by transglycosylation even though cross-linking was inhibited. Whole cells treated with penicillin excreted uncrosslinked peptidoglycan (Mirelman, Bracha \& Sharon, 1974b).

The studies of Mirelman did not indicate the length of the glycan chains that were being synthesized, either as free polymers or linked to the existing wall. Neither did they examine the degree of peptide cross-linking of the newly added chains, nor the extent to which some of these chains might have been removed to yield unsubstituted $N$-acetylmuramyl residues in the glycan chain. Work with Bacillus licheniformis has shown how the length of newly synthesized peptidoglycan chains can be established (Ward, 1973) and has also indicated a mode of addition of disaccharide units in which the glycan chain grows at the reducing end (Ward \& Perkins, 1973). The present paper examines the length and direction of synthesis of the new glycan chains produced in a wall + membrane preparation from Micrococcus luteus and also the proportion of unsubstituted disaccharide units that appear within it. The effect of penicillin on these processes is examined, and the influence of autolytic activity, not normally considered to be characteristic of this organism but particularly evident in the presence of the antibiotic, is also studied.

\section{METHODS}

All chemicals used were analytical grade unless otherwise stated. Benzylpenicillin (Crystapen) was from Glaxo; vancomycin hydrochloride (Vancocin $\mathrm{HCl}$ ) was a gift from Eli Lilly and Co., Basingstoke, Hampshire; UDP- $N$-acetylglucosamine was from Sigma; and lysozyme was from Armour Pharmaceutical Co., Eastbourne, Sussex. UDP- $N$-acetyl $\left[{ }^{14} \mathrm{C}\right]-$ glucosamine $\left(265 \mathrm{mCi} \mathrm{mmol}^{-1}\right)$ and $\mathrm{L}-\left[\mathrm{U}-{ }^{14} \mathrm{C}\right]$ lysine monohydrochloride $\left(348 \mathrm{mCi} \mathrm{mmol}^{-1}\right)$ were purchased from The Radiochemical Centre, Amersham.

Organisms. Micrococcus luteus NCTC2665 and Staphylococcus aureus $\mathrm{H}$ were laboratory cultures maintained on broth agar slants with monthly transfers.

Media and culture conditions. Cultures of $M$. luteus $(150 \mathrm{ml})$ were grown with shaking at $37^{\circ} \mathrm{C}$ in Hedley Wright medium (Wright, 1933) overnight. These cultures were used to inoculate larger batches of medium (2 1) containing (\%,w/v): Difco Bacto-peptone, 0.5 ; BBL yeast extract, 0.2 ; sodium chloride, 0.5 ; and glucose, 0.5 . Organisms were harvested in the mid-exponential phase of growth, several hours after addition of a $5 \%(\mathrm{v} / \mathrm{v})$ inoculum.

Cultures of $S$. aureus $\mathrm{H}(50 \mathrm{ml})$, used to accumulate nucleotides, were grown overnight in medium containing $(\%, \mathrm{w} / \mathrm{v})$ : Difco Bacto-peptone, 0.5 ; BBL yeast extract, 0.5 ; and $\mathrm{K}_{2} \mathrm{HPO}_{4}, \mathrm{O} \cdot \mathrm{I}$. These cultures were used as an inoculum for larger batches of fresh medium.

Preparation of substrates. UDP- $N$-acetyl $\left[{ }^{14} \mathrm{C}\right]$ muramyl-L-alanyl-D-isoglutamyl-L-lysyl-Dalanyl-D-alanine, referred to as UDP- $\left[{ }^{14} \mathrm{C}\right]$ MurNAc-pentapeptide, was prepared from $S$. aureus $\mathrm{H}$ inhibited by vancomycin and chloramphenicol in the presence of $\mathrm{D}-\left[\mathrm{U}-{ }^{14} \mathrm{C}\right]$ glucose, as described by Ward (1974)for the corresponding compound containing diaminopimelic acid. The product had a specific activity of I I $\cdot 0$ d.p.m. pmol $^{-1}$ and $80 \%$ of the total radioactivity was shown to reside in muramic acid. UDP- $N$-acetylmuramyl-L-alanyl-D-isoglutamyl-L-[ $\left.{ }^{14} \mathrm{C}\right]$ lysyl-D-alanyl-D-alanine (specific activity $28 \cdot 0$ d.p.m. pmol $^{-1}$ ), referred to as UDP-MurNAc- $\left[l_{y s-}{ }^{14} \mathrm{C}\right]$ pentapeptide, was prepared similarly, as was the unlabelled UDPMurNAc-pentapeptide.

Preparation of enzymes. Crude wall + membrane preparations were isolated as described by Mirelman, Shaw \& Park (1970). Cells of $M$. luteus were harvested in the early-exponential phase and disrupted by grinding with alumina at $4{ }^{\circ} \mathrm{C}$. The fraction sedimenting between 3000 and $12000 \mathrm{~g}$ was used as the crude wall preparation. Such preparations 
contained fragments of membrane firmly attached to walls (Mirelman et al., 1972) and free membrane fragments. The crude wall + membrane preparations were washed once in $50 \mathrm{mM}-$ Tris/HCl buffer, $\mathrm{pH} 7 \cdot 8$, containing $20 \mathrm{mM}^{-} \mathrm{MgCl}_{2}$ and $\mathrm{I} \mathrm{mM-2-mercaptoethanol} \mathrm{(TMM}$ buffer) and resuspended in the same buffer to give a final protein concentration of 3 to 7 $\mathrm{mg} \mathrm{ml}{ }^{-1}$. Wall + membrane preparations were isolated afresh for each incorporation of nucleotides.

Determination of enzyme activity in wall + membrane preparations. The complete reaction mixture contained (in a final volume of $200 \mu \mathrm{l}$ ) $50 \mathrm{~mm}$-Tris/ $\mathrm{HCl}\left(\mathrm{pH} 7 \cdot 8\right.$ ), $20 \mathrm{mM}-\mathrm{MgCl}_{2}$,

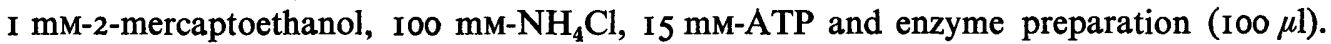
Radioactively labelled and unlabelled substrates were added as indicated and incubated at $28{ }^{\circ} \mathrm{C}$ for $30 \mathrm{~min}$ : (i) UDP- $N$-acetyl $\left.\left[{ }^{14} \mathrm{C}\right] \mathrm{g}\right]$ ucosamine (Io nmol, $32 \cdot 0$ d.p.m. pmol ${ }^{-1}$ ), UDP-MurNAc-pentapeptide (100 nmol) and glycine (500 nmol); (ii) UDP- $N$-acetylglucosamine (roo nmol), UDP-[ $\left.{ }^{14} \mathrm{C}\right]$ MurNAc-pentapeptide $\left(28 \mathrm{nmol}\right.$, I I $\cdot 0$ d.p.m. $\left.\mathrm{pmol}^{-1}\right)$ and glycine (500 nmol); (iii) UDP- $N$-acetylglucosamine (100 nmol), UDP-MurNAc- $\left[l y s-{ }^{14} \mathrm{C}\right]$ pentapeptide $\left(7.6 \mathrm{nmol}, 28 \mathrm{~d}\right.$.p.m. $\left.\mathrm{pmol}^{-1}\right)$ and glycine $(500 \mathrm{nmol})$. Reactions were stopped by adding $0.2 \mathrm{ml}$ 10 \% (w/v) sodium dodecyl sulphate (SDS). The suspension was centrifuged for $4 \mathrm{~min}$ in a Unipan model 320 microcentrifuge. The clear supernatant fluid was transferred to a cooled centrifuge tube. The SDS, brought out of solution by cooling to $4{ }^{\circ} \mathrm{C}$, was sedimented by centrifuging and the supernatant fluid was applied to the origin of a paper chromatogram and run in solvent $B$. The material remaining on the origin was either counted directly in toluene scintillant or eluted from the paper with water and counted in dioxan scintillant. The remaining wall pellet was resuspended in $0.5 \mathrm{ml}$ TMM buffer containing I $\%(w / v)$ SDS and washed four times with the same buffer. It was then resuspended in TMM buffer $(0.5 \mathrm{ml})$ plus $\mathrm{I} \% \mathrm{SDS}$ and heated $\left(100^{\circ} \mathrm{C}\right)$ for $15 \mathrm{~min}$. After cooling, the walls were washed once in TMM buffer and twice in water $(0.5 \mathrm{ml})$. They were resuspended in $0.5 \mathrm{ml}$ water and the radioactivity of a suitable sample suspended in dioxan scintillant was measured. Agreement between replicate samples was very close.

Measurement of chain lengths by boro $\left[{ }^{3} \mathrm{H}\right]$ hydride reduction. Purified SDS-soluble and SDS-insoluble peptidoglycans, labelled with ${ }^{14} \mathrm{C}$ in the muramyl residues, were prepared as above. Each purified peptidoglycan was treated with $0.1 \mathrm{M}-\mathrm{HCl}$ for $2 \mathrm{~h}$ at $60^{\circ} \mathrm{C}$. The acid was then removed by rotary evaporation and the samples were reduced with $\mathrm{KB}^{3} \mathrm{H}_{4}$ (Io $\mu \mathrm{Ci} \mu \mathrm{mol}^{-1}$ ) in dilute $\mathrm{NaOH}$ at $4{ }^{\circ} \mathrm{C}$ for $6 \mathrm{~h}$ (Ward, 1973). Excess $\mathrm{KB}^{3} \mathrm{H}_{4}$ was destroyed by the addition of dilute $\mathrm{HCl}$ followed by drying in vacuo. The SDS-insoluble (cross-linked) material was washed twice with water.

Both the SDS-soluble and SDS-insoluble materials were then subjected to acid hydrolysis $\left(3 \mathrm{M}-\mathrm{HCl}, 100{ }^{\circ} \mathrm{C}, 3 \mathrm{~h}\right.$ ) in sealed tubes. The acid was removed under vacuum over $\mathrm{NaOH}$ pellets and this process was repeated twice after addition of water. Finally samples were prepared in $0.5 \mathrm{ml}$ pyridine acetate buffer $(0 . \mathrm{I} \mathrm{M}, \mathrm{pH} 2.8)$, and applied to a column $(0.8 \times 20 \mathrm{~cm})$ of Dowex 50 (X2,200 to 400 mesh) equilibrated in the same buffer, with which the column was then eluted; $2 \mathrm{ml}$ fractions were collected. Samples $(0 \cdot 1 \mathrm{ml})$ were dried under vacuum over $\mathrm{P}_{2} \mathrm{O}_{5}$, and then counted in dioxan scintillant. Two radioactive peaks corresponding to muramitol (labelled with both ${ }^{14} \mathrm{C}$ and ${ }^{3} \mathrm{H}$ ) and muramic acid (labelled with ${ }^{14} \mathrm{C}$ only) were obtained. Fractions corresponding to each peak were pooled and run separately on Whatman $3 \mathrm{MM}$ paper in solvent $\mathrm{C}$ overnight with a $\left[{ }^{14} \mathrm{C}\right]$ muramitol standard. The chromatogram was cut into $0.5 \mathrm{~cm}$ strips which were counted in toluene scintillant.

Degradation of the reducing terminal $N$-acetylmuramyl peptide unit. Purified SDS-soluble and SDS-insoluble peptidoglycans, labelled with ${ }^{14} \mathrm{C}$ in the lysine residues, were prepared as above. Most samples were treated with $0 \cdot \mathrm{I} \mathrm{M}-\mathrm{HCl}$ at $60^{\circ} \mathrm{C}$ for $2 \mathrm{~h}$, and then dried over 
$\mathrm{NaOH}$ under vacuum. Some samples were not hydrolysed with acid in order to determine whether the reducing group on the terminal muramyl residue of the glycan was blocked (Ward \& Perkins, I973). All samples were further treated with $4 \mathrm{M}-\mathrm{NH}_{4} \mathrm{OH}$ in stoppered vessels at $37^{\circ} \mathrm{C}$ for $6 \mathrm{~h}$ to obtain $\beta$-elimination of the $3-O$ substituent on the reducing muramyl residue (Ghuysen et al., I967; Perkins, I967; Tipper, 1968). The samples were then transferred to the origin of a chromatogram on Whatman no. 3 paper and developed in solvent A. After thorough drying, the chromatogram was cut into I $\mathrm{cm}$ strips which were placed in scintillation vials and counted in toluene scintillant.

Analytical methods. Protein was determined by the method of Lowry et al. (195I) with bovine serum albumin as standard. Amino sugars and amino acids present in nucleotides and in disaccharide-pentapeptide (isolated from lysozyme digests) were determined using a Beckman-Spinco automatic amino-acid analyser after hydrolysing the samples in $4 \mathrm{M}-\mathrm{HCl}$ for $4 \mathrm{~h}$ at $100^{\circ} \mathrm{C}$ (for amino sugars) or $6 \mathrm{M}-\mathrm{HCl}$ for $\mathrm{I} 6 \mathrm{~h}$ at $105^{\circ} \mathrm{C}$ (for amino acids). $\mathrm{N}$-Acetylhexosamines were determined by the method of Reissig, Strominger \& Leloir (1955).

Radioactivity on paper chromatograms was located by a Packard radiochromatogram scanner or $\mathrm{I} \mathrm{cm}$ strips were cut out and counted directly in a Packard liquid scintillation counter using a toluene-based scintillation fluid [toluene containing $0.4 \%(\mathrm{w} / \mathrm{v})$ 2,5diphenyloxazole and $0.01 \%$ (w/v) I,4-bis-(4-methyl-5-phenyloxazol-2-yl)benzene]. The efficiency of counting was $63 \%$ for ${ }^{14} \mathrm{C}$ and $8 \%$ for ${ }^{3} \mathrm{H}$. Samples in aqueous solution were counted with a dioxan-based scintillation fluid [dioxan containing $18 \%(\mathrm{w} / \mathrm{v})$ naphthalene, $0.4 \%$ (w/v) 2,5-diphenyloxazole and $0.01 \%$ (w/v) 1,4-bis-(4-methyl-5-phenyloxazol-2-yl)benzene]. Efficiencies were $80 \%$ for ${ }^{14} \mathrm{C}$ and $30 \%$ for ${ }^{3} \mathrm{H}$.

Paper chromatography and electrophoresis. Whatman no. 3 and 3MM papers were washed extensively with I M-ammonium acetate and water before use. Descending paper chromatography was carried out in the following solvent systems: A, isobutyric acid/0.5 M-ammonia $(5: 3, \mathrm{v} / \mathrm{v}) ; \mathrm{B}$, ethanol/1 M-ammonium acetate $(5: 2, \mathrm{v} / \mathrm{v}) ; \mathrm{C}$, n-butanol/acetic acid/water (3: I : I, by vol.). Electrophoresis was carried out at $80 \mathrm{~V} \mathrm{~cm}^{-1}$ on Whatman $3 \mathrm{MM}$ paper in the buffer system: $\mathrm{D}$, pyridine/acetic acid/water $(25: 1: 474$, by vol.) $\mathrm{pH} 6 \cdot 5$.

Nucleotides were located by absorption of ultraviolet light, and amino acids and amino sugars with ninhydrin. Reducing groups of sugars on paper were detected with $0 \cdot \mathrm{I} \%(\mathrm{v} / \mathrm{v})$ saturated aqueous $\mathrm{AgNO}_{3}$ in acetone and developed in $0.5 \%(\mathrm{w} / \mathrm{v})$ methanolic $\mathrm{KOH}$.

Source of marker compounds. Purified walls were isolated from cultures of $M$. luteus grown to the late-exponential phase by disruption of the cells with ballotini glass beads (no. I2) and differential centrifuging. The wall fraction, which sedimented at I $2000 \mathrm{~g}$ but not at $5000 \mathrm{~g}$, was resuspended in buffer containing $4 \%(\mathrm{w} / \mathrm{v})$ SDS. The purified walls were then washed extensively with water and freeze-dried for storage. Disaccharide ( $N$-acetylglucosaminyl- $N$-acetylmuramic acid) and the disaccharide pentapeptide GP2 (Mirelman \& Sharon, 1967) were prepared by lysozyme digestion of purified walls. The diffusible material was separated into its various components by paper chromatography and electrophoresis at $80 \mathrm{~V} \mathrm{~cm}^{-1}$ on Whatman $3 \mathrm{MM}$ paper in buffer D. Lysozyme digests (500 $\mu \mathrm{g}$ lysozyme $\mathrm{ml}^{-1}$ for $48 \mathrm{~h}$ in sodium phosphate buffer $\mathrm{pH} \mathrm{6.5)}$ or radioactively labelled peptidoglycan were separated by electrophoresis in buffer $\mathrm{D}$ or by chromatography in solvent $\mathrm{A}$.

SDS-soluble material was digested with Myxobacter AL I enzyme (Ensign \& Wolfe, 1966) in $0.05 \mathrm{M}$-Tris/ $\mathrm{HCl}$ buffer, $\mathrm{pH} 9 \cdot 0$, for $24 \mathrm{~h}$. 


\section{RESULTS}

\section{Incorporation of labelled nucleotide into walls}

The newly synthesized peptidoglycan cross-linked to existing wall was purified by extensive washing with TMM buffer containing I \% SDS. Regardless of whether the UDPMurNAc-pentapeptide or UDP- $N$-acetylglucosamine was radioactive, approximately $2000 \mathrm{pmol}$ was incorporated per $\mathrm{mg}$ of membrane protein in $30 \mathrm{~min}$. As implied by the results of Mirelman et al. (I974a), wall + membrane preparations synthesized not only cross-linked material but also linear uncross-linked peptidoglycan, found in the supernatant fluids of incubation mixtures. The ratio of the SDS-soluble material to the total peptidoglycan synthesized depended on the state of the crude enzyme preparation. Vigorous grinding with alumina freed more membrane from the wall, consequently increasing the proportion of SDS-soluble material. In most experiments, SDS-soluble material represented 55 to $65 \%$ of the total synthesized glycan; however, values as high as $80 \%$ have been obtained. There was no evidence to suggest that the SDS-soluble material was ever cross-linked to existing wall. Indeed an experiment in which crude enzyme preparations were incubated for various times between 30 and $120 \mathrm{~min}$ indicated that the two types of synthesis were not interrelated. The synthesis of SDS-soluble material was paralleled by that of cross-linked material during the $2 \mathrm{~h}$ incubation and the ratio of SDS-soluble material to total peptidoglycan synthesized remained almost constant throughout, providing no indication of a precursorproduct relationship. To determine whether SDS-soluble material could serve as a substrate for cross-linking, ${ }^{14} \mathrm{C}$-labelled SDS-soluble peptidoglycan was purified as before and incubated with a fresh wall + membrane preparation. No nucleotide precursors were added to the incubation mixture. Only 34 pmol of soluble peptidoglycan was cross-linked to existing wall, whereas when peptidoglycan was newly synthesized from nucleotide precursors, 228I pmol was rendered insoluble by cross-linking. In another experiment, the fraction collected as a pellet between 12000 and $40000 \mathrm{~g}$ was used as a source of enzyme. This synthesized SDS-soluble peptidoglycan but did not link it to SDS-purified walls (4 mg) which were added to the incubation mixture. The total radioactivity found in the soluble material was 17970 d.p.m., whereas that associated with the purified wall (extensively washed with SDS after incubation for $30 \mathrm{~min}$ ) was $16 \mathrm{I}$ d.p.m. Hence peptidoglycan was synthesized by the membrane preparation but this material was not cross-linked to the added walls. This showed that the wall/membrane interface must remain intact for cross-linking of nucleotides to existing walls to occur.

Lysozyme digestions were carried out to determine the degree of cross-linking in newly synthesized peptidoglycan (Mirelman et al., 1974a). SDS-soluble peptidoglycan synthesized from UDP- $N$-acetyl $\left[{ }^{14} \mathrm{C}\right]$ glucosamine yielded, after lysozyme digestion, a single radioactive spot $\left(R_{F} 0.53\right)$ on chromatography in solvent $\mathrm{A}$. The product had the same chromatographic and electrophoretic properties as the GP2 fragment (Mirelman \& Sharon, 1967). There was no sign of any unsubstituted disaccharide, $N$-acetylglucosaminyl- $N$-acetylmuramic acid, nor of any cross-linked material. On the other hand, lysozyme digestion of cross-linked peptidoglycan labelled with UDP- $N$-acetyl $\left[{ }^{14} \mathrm{C}\right]$ glucosamine revealed several radioactive spots on electrophoresis in buffer $\mathrm{D}$. The spot with the greatest mobility towards the anode was identical with that from authentic disaccharide ( $N$-acetylglucosaminyl- $N$-acetylmuramic acid) prepared by lysozyme digestion of walls of $M$. luteus (Perkins, 1960). This material was also observed, but not measured, by Mirelman et al. (1974a). The disaccharide is believed to arise from the action of an amidase (Ghuysen et al., 1968; Mirelman et al., $1974 b$ ). In two separate experiments the disaccharide represented 15 and $20 \%$ of the total 
Table I. Is the reducing group of SDS-soluble peptidoglycan blocked during synthesis?

\begin{tabular}{|c|c|c|c|}
\hline $\begin{array}{l}\text { SDS-soluble peptidoglycan wa } \\
\text { was stopped by heating at } \mathrm{IO} \\
\text { was treated with } 4 \mathrm{M}-\mathrm{NH}_{4} \mathrm{OH} \\
\text { The radioactivity in } \mathrm{I} \mathrm{cm} \text { stri } \\
\text { toluene scintillant. }\end{array}$ & $\begin{array}{l}\text { d with UD } \\
5 \text { min. Aft } \\
\text { without pri } \\
\text { chromatog }\end{array}$ & $\begin{array}{l}{\left[\text { lys }{ }^{14} \text { C]pentaper }\right.} \\
\text { on by chromato } \\
\text { hydrolysis }(0 \cdot 1 \\
\text { ped in solvent }\end{array}$ & $\begin{array}{l}\text { le. The reaction } \\
\text { phy, the sample } \\
\left.\mathrm{HCl}, 60^{\circ} \mathrm{C}, 2 \mathrm{~h}\right) \\
\text { Nas measured in }\end{array}$ \\
\hline & ${ }^{14} \mathrm{C}$ radioac & porated (c.p.m.) & $\begin{array}{l}\text { Apparent av. } \\
\text { biosynthetic }\end{array}$ \\
\hline Treatment & Total & In lactyl peptide & (disaccharide units) \\
\hline Without acid hydrolysis & 36 I 20 & 397 & 9I \\
\hline With acid hydrolysis & 36120 & 2168 & 17 \\
\hline
\end{tabular}

radioactivity found in cross-linked peptidoglycan. Thus the proportion of unsubstituted disaccharide units found in peptidoglycan synthesized and cross-linked in vitro was very low compared with that found in the walls of whole organisms, where the value is approximately $50 \%$ (Ghuysen et al., I968).

\section{Is the reducing group of the SDS-soluble peptidoglycan blocked during synthesis?}

A fresh wall + membrane preparation was incubated with UDP-MurNAc- $\left[l y s-{ }^{14} \mathrm{C}\right]$ pentapeptide and other substrates as before. Very little lactyl peptide was freed by direct $\beta$-elimination, whereas after mild acid hydrolysis $\left(0 \cdot \mathrm{I} \mathrm{M}-\mathrm{HCl}, 60^{\circ} \mathrm{C}, 2 \mathrm{~h}\right)$ there was a large increase in the number of lactyl peptides released by $\beta$-elimination (Table $\mathrm{I}$ ). Clearly, as in B. licheniformis (Ward \& Perkins, I 973), the reducing group of the terminal muramyl residue was blocked by a linkage which was labile to mild acid hydrolysis. It seems probable that this linkage was the same as that found between the disaccharide hexapeptide and the lipid intermediate during peptidoglycan synthesis. Consequently for estimation of chain lengths of newly synthesized peptidoglycan, mild acid hydrolysis was routinely included.

\section{Estimation of the average biosynthetic chain length}

$\beta$-Elimination of SDS-soluble peptidoglycan labelled with ${ }^{14} \mathrm{C}$ in the lysine residue gave values for the chain lengths of 25 and 28 disaccharide units (Table 2). This agreed closely with the value obtained by potassium boro $\left[{ }^{3} \mathrm{H}\right]$ hydride reduction. UDP- $\left[{ }^{14} \mathrm{C}\right] \mathrm{MurNAc}-$ pentapeptide was incorporated into newly synthesized peptidoglycan by wall + membrane preparations, so that the muramyl residues of new peptidoglycan were labelled with ${ }^{14} \mathrm{C}$. After treatment with potassium boro $\left[{ }^{3} \mathrm{H}\right]$ hydride, acid hydrolysis of the peptidoglycan gave $\left[{ }^{14} \mathrm{C},{ }^{3} \mathrm{H}\right]$ muramitol and $\left[{ }^{14} \mathrm{C}\right]$ muramic acid, which were separated by column and paper chromatography. The average biosynthetic chain lengths were calculated by dividing the total radioactivity attributed to ${ }^{14} \mathrm{C}$ by the amount found in muramitol. For SDS-soluble material the biosynthetic chain length was 26 disaccharide units and for cross-linked material it was 66 disaccharide units (Table 3). However, the latter did not correspond to that obtained by the $\beta$-elimination method (Table 2). The number of lactyl peptides set free by $\beta$-elimination was smaller than expected from the number of free reducing groups. This result suggests that many of the disaccharide hexapeptide units were cross-linked almost immediately to existing wall and thus were not freed by $\beta$-elimination. 
Table 2. Estimation of the average chain length of newly synthesized peptidoglycan:

$$
\beta \text {-elimination of peptide side chains }
$$

SDS-soluble and cross-linked peptidoglycans labelled with UDP-MurNAc- $\left[\right.$ lys $\left.{ }^{14} \mathrm{C}\right]$ pentapeptide were purified and subjected to mild acid hydrolysis $\left(0 \cdot \mathrm{I} \mathrm{M}-\mathrm{HCl}, 60^{\circ} \mathrm{C}, 2 \mathrm{~h}\right)$ followed by $4 \mathrm{M}-\mathrm{NH}_{4} \mathrm{OH}$. Chromatograms of the supernatant fluid from the cross-linked material and of the SDS-soluble material were developed in solvent $\mathbf{A}$, and then cut into $\mathrm{I} \mathrm{cm}$ strips which were counted in toluene scintillant.

$\begin{array}{lccc}\text { Total } & \text { In lactyl peptide } & \begin{array}{c}\text { Av. biosynthetic } \\ \text { chain length } \\ \text { (disaccharide units) }\end{array} \\ \text { SDS-soluble } & 18555 & 681 & 28 \\ \text { Cross-linked } & 10515 & 426 & 25 \\ & 32875 & 184 & 178\end{array}$

Table 3. Estimation of the average length of newly synthesized peptidoglycan by potassium boro $\left[{ }^{3} \mathrm{H}\right]$ hydride reduction, and the effect of benzylpenicillin

SDS-soluble and wall-linked peptidoglycans were labelled with UDP-[ $\left.{ }^{14} \mathrm{C}\right]$ MurNAc-pentapeptide with or without benzylpenicillin $\left(100 \mu \mathrm{g} \mathrm{ml}^{-1}\right)$. After mild acid hydrolysis, samples were reduced with $\mathrm{KB}^{3} \mathrm{H}_{4}$. Further strong acid hydrolysis gave muramitol and muramic acid which were separated by column and paper chromatography. The radioactivity of paper strips was measuredas in Methods.

$\begin{array}{lccc} & \begin{array}{c}\text { Muramic acid } \\ \text { + muramitol }\end{array} & \text { Muramitol } & \begin{array}{c}{ }^{14} \text { C radioactivity incorporated (c.p.m.) in: } \\ \text { chain length } \\ \text { (disaccharide units) }\end{array} \\ \begin{array}{l}\text { SDS-soluble } \\ \text { Wall-linked }\end{array} & 7085 & 278 & 26 \\ \text { Wall-linked, in the } & 7644 & 116 & 66 \\ \text { presence of penicillin } & 5396 & 178 & 30 \\ \text { (2 expts) } & 3552 & 79 & 45\end{array}$

\section{The effect of penicillin on incorporation of labelled nucleotides into cross-linked} material

Mirelman et al. (1972) showed that incorporation into cross-linked peptidoglycan was inhibited by not more than about $70 \%$ by benzylpenicillin and proposed that the residual radioactivity was linked to existing wall by a transglycosylation reaction. In our hands, the maximum inhibition of incorporation of UDP- $N$-acetyl $\left[{ }^{14} \mathrm{C}\right]$ glucosamine into cross-linked material, even in the presence of high concentrations of penicillin, was $74 \%$. However, overall glycan synthesis, as measured by the total radioactivity in newly synthesized peptidoglycan, was unaffected by penicillin except slightly at the highest concentrations (Fig. I). This was in agreement with experiments which showed that whole cells treated with penicillin released soluble peptidoglycan into the medium (Mirelman et al., I974b; Tynecka \& Ward, 1975).

\section{Estimation of the lengths of glycan chains added by transglycosylation}

Radioactivity from UDP- $\left[{ }^{14} \mathrm{C}\right]$ MurNAc-pentapeptide was incorporated into wall + membrane preparations in the presence of $100 \mu \mathrm{g}$ benzylpenicillin $\mathrm{ml}^{-1}$ and walls were purified with SDS as before. Under these conditions the radioactivity found in the wall fraction was presumably linked by transglycosylation. The lengths of the glycan chains were measured 


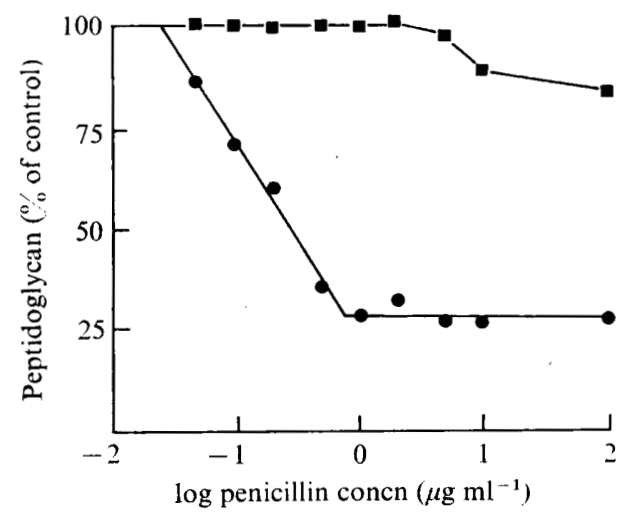

Fig. I. Effect of benzylpenicillin on the incorporation of UDP- $N$-acetyl[ $\left[{ }^{14} \mathrm{C}\right]$ glucosamine into newly synthesized peptidoglycan. Standard assay mixtures with added benzylpenicillin were incubated at $28^{\circ} \mathrm{C}$ for $30 \mathrm{~min}$. Enzyme activity was halted by the addition of SDS and crosslinked and soluble peptidoglycans were purified. Radioactivity was measured in the cross-linked material and the SDS-soluble peptidoglycan. The graphs show the total peptidoglycan synthesized $(\boldsymbol{C})$ and the proportion that was cross-linked (O). Results are expressed as a percentage of the control without penicillin.

by $\mathrm{KB}^{3} \mathrm{H}_{4}$ reduction as before. On average, between 30 and 45 disaccharide units were linked to nascent chains of the existing walls by transglycosylation during 30 min incubation (Table 3). Since these new chains were attached to the existing peptidoglycan only by transglycosylation, the fact that they contained a proportion of muramyl residues which, after mild acid hydrolysis, could be reduced by $\mathrm{KB}^{3} \mathrm{H}_{4}$ showed that the direction of extension must be by addition of new units at the reducing end of the glycan chains, as previously found in B. licheniformis (Ward \& Perkins, 1973). The growing glycan chains must still have remained attached at their reducing ends to some acid-labile linkage. Had new disaccharide units been added at the non-reducing terminal, by substitution of C-4 of an $\mathrm{N}$-acetylglucosamine residue, then mild acid hydrolysis would not have released any reducing groups of muramic acid.

\section{Measurement of autolytic activity by a wall + membrane preparation induced by penicillin}

Incubation mixtures containing UDP- $N$-acetyl $\left[{ }^{14} \mathrm{C}\right]$ glucosamine, with or without benzylpencillin ( $100 \mu \mathrm{g} \mathrm{ml}^{-1}$ ), were incubated for between 30 and $120 \mathrm{~min}$. The rate of incorporation of radioactivity into newly synthesized peptidoglycan linked to existing wall decreased with time, either with or without penicillin, and the incorporation of UDP- $N$-acetyl[ $\left.{ }^{14} \mathrm{C}\right] \mathrm{glu}-$ cosamine during the final $30 \mathrm{~min}$ of incubation was determined for each incubation mixture (Table 4). The proportion of radioactivity attributable to attachment by transglycosylation (that found when penicillin was present) decreased from $25 \%$ in the first 30 min to only $12 \%$ in the last $30 \mathrm{~min}$ of a $2 \mathrm{~h}$ incubation. This result suggested that the ability of the preparation to attach new chains by transglycosylation deteriorated faster than its power to transpeptidate. This possibility was tested by conducting the experiment in another way. Complete incubation mixtures containing unlabelled UDP- $N$-acetylglucosamine and benzylpenicillin (100 $\mu \mathrm{g} \mathrm{ml}^{-1}$ ) were incubated for either 30,60 or $90 \mathrm{~min}$ and then labelled for the next 30 min with UDP- $N$-acetyl $\left[{ }^{14} \mathrm{C}\right]$ glucosamine (Table 4 ). Under these circumstances the sum of the incorporation during the four successive $30 \mathrm{~min}$ periods of incubation (i.e. I $20 \mathrm{~min}$ in all) was $1032 \mathrm{pmol}$, compared with the apparent incorporation of only $737 \mathrm{pmol}$ 


\section{Table 4. Estimation of autolytic activity in a wall + membrane preparation expressed in the presence of penicillin}
Standard assay mixtures were set up, containing $25 \mathrm{nmol}$ UDP- $N$-acetyl $\left[{ }^{14} \mathrm{C}\right]$ glucosamine (I I d.p.m. pmol ${ }^{-1}$ ) and $100 \mu \mathrm{l}$ of wall + membrane preparation (protein concentration $5.2 \mathrm{mg}$ $\mathrm{ml}^{-1}$ ). Transglycosylation was measured in the presence of penicillin (100 $\left.\mu \mathrm{g} \mathrm{ml}^{-1}\right)$. Other assay mixtures were pre-incubated with penicillin and UDP- $N$-acetylglucosamine $(25 \mathrm{nmol})$ for 30,60 or $90 \mathrm{~min}$ and then labelled with UDP- $N$-acetyl[ $\left.{ }^{4} \mathrm{C}\right]$ glucosamine for $30 \mathrm{~min}$. The added radioactive compound did not appreciably affect the overall concentration. The numbers in parentheses represent the proportion of peptidoglycan linked by transglycosylation as a percentage of the total cross-linked material.

$0-30$
$30-60$
$60-90$
$90-120$
New peptidoglycan cross-linked to walls (penicillin absent) in final $30 \mathrm{~min}$ (pmol)

1416
1047
770
704
New peptidoglycan linked to walls by transglycosylation in final $30 \mathrm{~min}$

$\begin{array}{cc}\begin{array}{c}\text { Incubated with UDP- } \\ {\left[\begin{array}{c}\left.{ }^{14} \mathrm{C}\right] \text { GlcNAc from start } \\ \text { of incubation (pmol) }\end{array}\right.}\end{array} & \begin{array}{c}\text { Incubated with } \\ {\left[{ }^{14} \mathrm{C}\right] \text { GlcNAc for la }} \\ \text { of incubation ( }\end{array} \\ 354(25) & - \\ \text { I96 (19) } & 257(25) \\ \text { IO6 (14) } & 212(28) \\ 8 \text { I (1 }) & 209(30)\end{array}$

observed when UDP- $N$-acetyl $\left[{ }^{14} \mathrm{C}\right]$ glucosamine was present throughout. Thus in the incubation mixture pre-incubated for $90 \mathrm{~min}$ with unlabelled UDP- $N$-acetylglucosamine, 209 pmol was attached by transglycosylation during the final 30 min incubation with UDP- $N$ acetyl $\left[{ }^{14} \mathrm{C}\right]$ glucosamine compared with an apparent value of $8 \mathrm{r}$ pmol when the labelled nucleotide was present throughout. These differences could be accounted for if in the presence of penicillin the newly synthesized peptidoglycan were being attacked by autolytic enzymes in the preparation, a supposition which further unpublished work has proved to be correct.

\section{DISCUSSION}

In the presence of penicillin, where attachment to existing peptidoglycan chains must be by transglycosylation, disaccharide peptide units were added to the reducing end of the growing glycan chains in wall + membrane preparations of $M$. luteus. The direction of synthesis shown here is consistent with that originally demonstrated for peptidoglycan synthesis by a membrane preparation of $B$. licheniformis (Ward \& Perkins, 1973). Similarly the reducing end of the growing glycan chain was blocked by a linkage which was labile to mild acid hydrolysis.

The glycan chain lengths in cross-linked peptidoglycan were about three times as long as in SDS-soluble peptidoglycan, which suggested that the membrane incorporated nucleotides more efficiently when the interface between the membrane and the wall remained intact. Correspondingly, the need for the integrity of the wall/membrane junction to permit cross-linking was shown by the following experiments. A membrane preparation did not cross-link newly synthesized peptidoglycan to added purified wall and conversely a wall + membrane preparation did not utilize SDS-soluble peptidoglycan as a substrate for transpeptidation. These results imply that the processes of synthesis and cross-linking are continuous and highly ordered.

Lysozyme digestion of SDS-soluble peptidoglycan yielded a single product, similar to the disaccharide hexapeptide obtained after digestion of soluble peptidoglycan excreted by whole cells in the presence of penicillin (Mirelman et al., 1974b). Digestion of cross-linked 
peptidoglycan gave several products including the unsubstituted disaccharide unit. The amount of disaccharide recovered from newly synthesized cross-linked peptidoglycan was smaller than would have been anticipated from a knowledge of the overall structure of completed wall (Leyh-Bouille et al., 1966). Either the activity of the amidase was decreased in the wall + membrane preparations relative to that in intact cells or the formation of a D-Ala-LLys linkage is the first step in the cross-linking mechanism. Recently, Jensen \& Campbell (1976) have shown such an amidase in exponential rather than stationary phase cells of $M$. luteus (sodonensis). Mirelman, Kleppe \& Jensen (1975) obtained evidence that some glycan chains may be stripped of peptides while others retain theirs almost intact.

The average biosynthetic chain lengths for SDS-soluble peptidoglycan were similar whether measured by boro $\left[{ }^{3} \mathrm{H}\right]$ hydride reduction or $\beta$-elimination. However, relatively few lactyl peptides were released by $\beta$-elimination of cross-linked peptidoglycan. This discrepancy could be due to cross-linking of peptide side chains to existing walls immediately after addition of the disaccharide unit to the growing glycan chain and before the addition of the next disaccharide unit. In this way side chains released from muramic acid reducing groups (after mild acid hydrolysis) by $\beta$-elimination would not be rendered soluble since their distal end would be attached by cross-linking to the insoluble wall. The discrepancy could also be due partly to the removal of the side chains from the reducing terminal muramic acid by an amidase. However, if this loss were random, the proportion of side chains lost in this way could only be $20 \%$ of the total, as estimated from the proportion of free disaccharides found in lysozyme digests. If allowance were made for this factor, the radioactivity of lactyl peptide (Table 2) could be corrected to 230 c.p.m. which would give a biosynthetic chain length of I43 units - still far greater than the result of 66 obtained by the boro[ $\left.{ }^{3} \mathrm{H}\right]-$ hydride reduction method.

Whole cells of $M$. luteus show little or no lytic activity. However, the addition of penicillin (100 $\mu \mathrm{g} \mathrm{ml}^{-1}$ ) to actively dividing cells causes slow cellular lysis. It seems likely that in normal cells the autolysin is repressed by some mechanism and the addition of penicillin removes this block. A similar general mechanism has been suggested for the action of penicillin on Streptococcus pneumoniae (Höltje \& Tomasz, 1975) although in that case lipoteichoic acid was implicated. Micrococcus luteus is reported to have no lipoteichoic acid, but rather a lipomannan (Pless, Schmit \& Lennarz, 1975; Owen \& Salton, 1975; Powell, Duckworth \& Baddiley, 1974).

The work described in this paper was carried out in part fulfilment of the requirements for a degree of Ph.D. in the University of Liverpool by A. Weston. The award of an MRC Research Studentship is gratefully acknowledged.

\section{REFERENCES}

Anderson, J. S., Matsuhashi, M., Haskin, M. A. \& STrominger, J. L. (1965). Lipid-phosphoacetylmuramyl-pentapeptide and lipid-phosphodisaccharide-pentapeptide: presumed membrane transport intermediates in cell wall synthesis. Proceedings of the National Academy of Sciences of the United States of America 53, 88I-889.

Anderson, J. S., Meadow, P. M., Haskin, M. A. \& Strominger, J. L. (I966). Biosynthesis of the peptidoglycan of bacterial cell walls. I. Utilization of uridine diphosphate acetylmuramyl-pentapeptide and uridine diphosphate acetylglucosamine for peptidoglycan synthesis by particulate enzymes from Staphylococcus aureus and Micrococcus lysodeikticus. Archives of Biochemistry and Biophysics 116, 487515.

ENSIGN, J. C. \& Wolfe, R. S. (I966). Characterization of a small proteolytic enzyme which lyses bacterial cell walls. Journal of Bacteriology 9r, 524-534. 
Ghuysen, J.-M., Bricas, E., Leyh-BouIlle, M., Lache, M. \& Shockman, G. D. (1967). The peptide $N^{\alpha}$ (L-alanyl-D-isoglutaminyl)- $N^{\epsilon}$-(D-isoasparaginyl)-L-lysyl-D-alanine and the disaccharide $N$-acetylglucosaminyl- $\beta$-I,4- $N$-acetylmuramic acid in cell wall peptidoglycan of Streptococcus faecalis strain ATCC 9790. Biochemistry 6, 2607-2619.

GHuYSEN, J.-M., Bricas, E., LACHE, M. \& LeyH-BOullle, M. (I968). Structure of the cell walls of Micrococcus lysodeikticus. III. Isolation of a new peptide dimer, $N^{\alpha}$-[L-alanyl- $\gamma-(\alpha-\mathrm{D}-$ glutamyl-glycine)]-L-lysyl-Dalanyl- $N^{\alpha}$-[L-alanyl- $\gamma$-( $\alpha$-D-glutamyl-glycine)]-L-lysyl-D-alanine. Biochemistry 7, 1450-1460.

HöltJe, J.-V. \& Tomasz, A. (1975). Lipoteichoic acid. A specific inhibltor of autolysin activity in Pneumococcus. Proceedings of the National Academy of Sciences of the United States of America 72, 1690-1694.

Jensen, S. E. \& CAMPBell, J. N. (1976). Amidase activity involved in peptidoglycan biosynthesis in membranes of Micrococcus luteus (sodonensis). Journal of Bacteriology 127, 319-326.

Leyh-Boutlle, M., Ghuysen, J.-M., Tipper, D. J. \& Strominger, J. L. (I966). Structure of the cell wall of Micrococcus lysodeikticus. I. Study of the structure of the glycan. Biochemistry 5, 3079-3090.

Lowry, O. H., Rosebrough, N. J., FarR, A. L. \& Randall, R. J. (I95I). Protein measurement with the Folin phenol reagent. Journal of Biological Chemistry 193, 265-275.

Mirelman, D. \& Sharon, N. (1967). Isolation and study of the chemical structure of low molecular weight glycopeptides from Micrococcus lysodeikticus cell walls. Journal of Biological Chemistry 242, 3414-3427.

Mirelman, D. \& Sharon, N. (1972). Biosynthesis of peptidoglycan by a cell wall preparation of Staphylococcus aureus and its inhibition by penicillin. Biochemical and Biophysical Research Communications 46, 1909-1917.

Mirelman, D., Shaw, D. R. D. \& Park, J. T. (1970). Nature and origins of phosphorus compounds in isolated cell walls of Staphylococcus aureus. Journal of Bacteriology 107, 239-244.

Mirelman, D., Bracha, R. \& SHARON, N. (1972). Role of the penicillin-sensitive transpeptidation reaction in attachment of newly synthesized peptidoglycan to cell walls of Micrococcus luteus. Proceedings of the National Academy of Sciences of the United States of America 69, 3355-3359.

Mirelman, D., Bracha, R. \& Sharon, N. (1974a). Studies on the elongation of bacterial cell wall peptidoglycan and its inhibition by penicillin. Annals of the New York Academy of Sciences 235, 326-347.

Mirelman, D., Bracha, R. \& Sharon, N. (1974 $b$ ). Penicillin-induced secretion of a soluble, uncross-linked

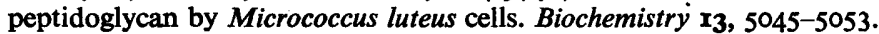

Mirelman, D., KLePPE, G. \& Jensen, H. B. (1975). Studies on the specificity of action of bacteriophage T4 lysozyme. European Journal of Biochemistry 55, 369-373.

OWEN, P. \& SAlton, M. R. J. (1975). A succinylated mannan in the membrane system of Micrococcus lysodeikticus. Biochemical and Biophysical Research Communications 63, 875-880.

Perkins, H. R. (1960). The structure of a disaccharide liberated by lysozyme from the cell walls of Micrococcus lysodeikticus. Biochemical Journal 74, 182-186.

PERKINS, H. R. (1967). The use of photolysis of dinitrophenylpeptides in structural studies on the cell wall mucopeptide of Corynebacterium poinsettiae. Biochemical Journal 102, 29c-32c.

Pless, D. D., Schmit, A. S. \& LenNARZ, W. J. (1975). The characterization of mannan of Micrococcus lysodeikticus as an acidic lipopolysaccharide. Journal of Biological Chemistry 250, 1319-1327.

Powell, D. A., Duckworth, M. \& Baddiley, J. (1974). An acylated mannan in the membrane of Micrococcus lysodeikticus. FEBS Letters 41, 259-263.

Reissig, J. L., Strominger, J. L. \& Leloir, L. F. (1955). A modified colorimetric method for the estimation of $N$-acetylamino sugars. Journal of Biological Chemistry 217, 959-966.

TIPPER, D. J. (1968). Alkali-catalysed elimination of D-lactic acid from muramic acid and its derivatives and the determination of muramic acid. Biochemistry 7, I44I-I449.

TYNECKA, Z. \& WARD, J. B. (1975). Peptidoglycan synthesis in Bacillus licheniformis. The inhibition of crosslinking by benzylpenicillin and cephaloridine in vivo accompanied by the formation of soluble peptidoglycan. Biochemical Journal 146, 253-267.

WARD, J. B. (1973). The chain length of the glycans in bacterial cell walls. Biochemical Journal 133, 395398.

WARD, J. B. (1974). The synthesis of peptidoglycan in an autolysin-deficient mutant of Bacillus licheniformis N.C.T.C. 6346 and the effect of $\beta$-lactam antibiotics, bacitracin and vancomycin. Biochemical Journal r4r, 227-24I.

WARD, J. B. \& Perkins, H. R. (I973). The direction of glycan synthesis in a bacterial peptidoglycan. Biochemical Journal r35, $72 \mathrm{I}-728$.

WRIGHT, H. D. (1933). The importance of adequate reduction of peptone in the preparation of media for the pneumococcus and other organisms. Journal of Pathology and Bacteriology 37, 257-282. 